\title{
The Relationship between Serum Insulin-Like Growth Factor-1 Levels and Body Composition Changes after Sleeve Gastrectomy
}

\author{
Masahiro Ohira ${ }^{a}$ Yasuhiro Watanabe ${ }^{b}$ Takashi Yamaguchi $^{b}$ Hiroki Onda $^{b}$ \\ Shuhei Yamaokab Kazuki Abe ${ }^{b}$ Shoko Nakamurab Shou Tanakab \\ Naoyuki Kawagoe ${ }^{a}$ Taiki Nabekurac ${ }^{c}$ Atsuhito Saiki ${ }^{b}$ Takashi Oshiroc

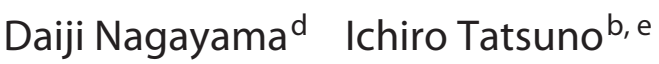 \\ aDivision of Diabetes, Metabolism and Endocrinology, Department of Internal Medicine, Toho University Ohashi \\ Medical Center, Tokyo, Japan; ${ }^{\mathrm{b} C e n t e r}$ for Diabetes, Endocrine and Metabolism, Toho University Sakura Medical \\ Center, Chiba, Japan; 'Department of Surgery, Toho University Sakura Medical Center, Chiba, Japan; ${ }^{\mathrm{d} D e p a r t m e n t}$ of \\ Internal Medicine, Nagayama Clinic, Tochigi, Japan; ${ }^{e}$ Chiba Prefectural University of Health Sciences, Chiba, Japan
}

\author{
Keywords \\ Laparoscopic sleeve gastrectomy · Insulin-like growth \\ factor-1 - Obesity · Body fat · Skeletal muscle
}

\begin{abstract}
Introduction: We previously reported that preoperative serum insulin-like growth factor-1 (IGF-1) is a predictor of total weight loss percentage (\%TWL) after laparoscopic sleeve gastrectomy (LSG). IGF-1 may suppress muscle loss after surgery. IGF-1 almost accurately reflects the growth hormone $(\mathrm{GH})$ secretion status, and $\mathrm{GH}$ has lipolytic effects. Therefore, IGF-1 may influence both the maintenance of skeletal muscle and the reduction of adipose tissue after LSG. The identification of the relationship between preoperative serum IGF1 and body composition changes after LSG can help in understanding the pathophysiology of obesity. Methods: We retrospectively reviewed 72 patients with obesity who underwent LSG and were followed up for 12 months. We analyzed the relationship between preoperative serum IGF-1
\end{abstract}

karger@karger.com www.karger.com/ofa

Karger $\stackrel{\text { ' }}{5}$

GOPEN ACCESS
(C) 2021 The Author(s)

Published by S. Karger AG, Basel

This is an Open Access article licensed under the Creative Commons Attribution-NonCommercial-4.0 International License (CC BY-NC) (http://www.karger.com/Services/OpenAccessLicense), applicable to the online version of the article only. Usage and distribution for commercial purposes requires written permission. levels and body composition changes after LSG. A multiple regression model was used. Results: LSG led to a significant reduction in body weight. Both body fat mass and skeletal muscle mass decreased after LSG. Preoperative serum IGF-1 levels significantly correlated with \%TWL, changes in skeletal muscle mass, and body fat mass after LSG. The multiple regression model showed that preoperative serum IGF-1 levels were related to decreased body fat mass and maintaining skeletal muscle mass after LSG. Discussion/Conclusion: Preoperative IGF-1 measurement helps predict not only successful weight loss but also decreases body fat mass and maintains skeletal muscle mass after LSG.

(c) 2021 The Author(s).

Published by S. Karger AG, Basel

\section{Introduction}

Laparoscopic sleeve gastrectomy (LSG) is among the most common and effective bariatric surgical procedures and leads to excess weight reductions of $47.2-83.3 \%$ one 
year after surgery [1-4]. The effect of LSG on body weight (BW) loss is superior to that of lifestyle modification and nonsurgical treatment $[5,6]$. Thus, LSG has excellent therapeutic effects against obesity. However, 18.5-46.2\% of cases show insufficient weight loss 2 years after LSG [7-9]; therefore, it is important to predict successful weight loss before LSG. Some preoperative clinical parameters, including age, sex, body mass index (BMI), presence of type 2 diabetes, serum triglyceride (TG), and glycosylated hemoglobin (HbAlc) have been reported as preoperative predictors of weight loss after bariatric surgery [10-14].

We previously reported that low preoperative serum insulin-like growth factor-1 (IGF-1) is related to insufficient weight loss after LSG [15]. IGF-1 is an anabolic hormone that may suppress muscle mass loss after surgery and increase energy expenditure [16, 17]; hence, serum IGF-1 is associated with weight loss after surgery. Further, IGF-1 is a growth hormone (GH)-dependent polypeptide, and circulating GH stimulates its synthesis and secretion from the liver [18]. IGF-1 reflects patient GH secretion status [19], and GH has lipolytic effects [20,21]. Therefore, serum IGF-1 levels may reflect the lipolytic action of GH. However, it remains unclear whether body composition of skeletal muscle or/and adipose tissue changes after LSG is associated with preoperative serum IGF-1 levels. Identifying the relationship between preoperative serum IGF-1 levels and body composition changes after LSG can help understand the pathophysiology of obesity. Therefore, this study aimed to investigate the relationship between preoperative serum IGF-1 levels and body composition changes after LSG.

\section{Materials and Methods}

\section{Study Design and Participants}

We retrospectively reviewed clinical data obtained between January 2014 and August 2019 at the Toho University Sakura Medical Center (Sakura City, Chiba, Japan) to identify patients treated for primary obesity (BMI of $32.0-34.9 \mathrm{~kg} / \mathrm{m}^{2}$ with at least 1 obesityrelated comorbidity or BMI $\geq 35 \mathrm{~kg} / \mathrm{m}^{2}$ at first visit) who underwent LSG and were followed up for 12 months after surgery. We excluded patients followed up for $<12$ months and patients whose body composition before and 12 months after LSG were not measured. Eighty-one patients underwent LSG during this period; 6 dropped out within 12 months after LSG. Body composition was not measured in 3 patients 12 months after LSG. Overall, 9 patients were excluded from this study. Seventy-two patients (88.9\% of patients who underwent LSG at our hospital) were ultimately included.

We compared the following parameters before and 12 months after LSG: BW, BMI, aspartate transaminase (AST), alanine transaminase (ALT), blood urea nitrogen, serum creatinine, estimated glomerular filtration rate (eGFR), total cholesterol, TG, high-density lipoprotein cholesterol, low-density lipoprotein cholesterol, fasting blood glucose, HbA1c, and body composition. Serum IGF1 levels were measured only at baseline because we measured hormone levels, including IGF-1 levels, to discriminate secondary obesity. The total weight loss percentage (\%TWL) was estimated 12 months after LSG. BW was measured, and blood samples were collected in the morning after a 12 -h fast.

\section{Measurement of Various Parameters}

Within $1 \mathrm{~h}$ of blood collection, serum and plasma were separated by centrifuging the specimen at 3,000 rpm for $10 \mathrm{~min}$. Serum was used to measure the levels of HbAlc, AST, ALT, blood urea nitrogen, creatinine, eGFR, lipids, and IGF-1. Serum IGF-1 levels were measured using the ECLusys ${ }^{\circledR}$ reagent IGF-1 assay kit (Roche Diagnostics, Basel, Switzerland). IGF-1 levels were measured at the LSI Medience Corporation (Tokyo, Japan). IGF-1 levels were measured using the cobas ${ }^{\circledR} 8000$ system (Roche Diagnostics, Basel, Switzerland).

Body composition was measured with direct segmental multifrequency bioelectrical impedance analysis (BIA)using InBody 720 (Biospace Co., Ltd. Chungcheongnam-do, Republic of Korea). The system separately measured the impedance of the participants' right arm, left arm, trunk, right leg, and left leg at 6 different frequencies $(1,5,50,250,500$, and $1,000 \mathrm{kHz})[22,23]$. Fat mass and skeletal muscle mass were normalized for height $(\mathrm{m})$ squared.

\section{Statistical Analyses}

Normality of the data distribution was tested using the ShapiroWilk test. Continuous data were expressed as median and interquartile range (IQR) because many variables were non-normally distributed. Paired sample data were analyzed using the Wilcoxon signed-rank test. Univariate analysis was performed using Spearman's rank correlation coefficient, owing to the nonparametric nature of the data. A multivariate analysis was used to analyze independent associations of variables with preoperative serum IGF-1 levels. Covariates were selected to assess the independent contributions of age, sex, and study outcomes (change in normalized fat mass and change in normalized skeletal muscle mass). Existence of type 2 diabetes was also included in the model according to prior published literature [24]. \%TWL, change in free fat mass, change in body fat mass, and change in skeletal muscle mass were excluded from the model because of influences of multicollinearity on change in normalized body fat mass and change in normalized skeletal muscle mass. $p$ values $<0.05$ were considered significant. All statistical analyses were performed using JMP software (version 14.2; SAS Institute, Cary, NC, USA).

\section{Results}

Table 1 shows patient baseline characteristics and changes in various parameters 12 months after LSG. In total, $59.7 \%(n=43)$ of the patients had type 2 diabetes. Median (IQR) age, BMI, HbA1c, and IGF-1 were 44.0 (37.0-51.8) years, $43.1(38.1-49.0) \mathrm{kg} / \mathrm{m}^{2}, 6.3 \%(5.8-$ $6.8 \%)$, and $108.5(81.5-138.8) \mathrm{ng} / \mathrm{mL}$, respectively. 
Table 1. Baseline characteristics and change in various parameters 12 months after LSG

\begin{tabular}{lllr}
\hline & Baseline & After 12 months & $p$ value $^{\mathrm{a}}$ \\
\hline $\begin{array}{l}\text { Participants, } n \\
\text { Sex (male/female), } n \text { (\%) }\end{array}$ & 72 & & \\
Type 2 diabetes, \% & $33(45.8) / 39(54.2)$ & & \\
\%TWL, \% & $59.7(43)$ & $29.3(22.6-35.3)$ & \\
IGF-1, ng/mL & & & \\
Age, years & $108.5(81.5-138.8)$ & & \\
BW, kg & $44.0(37.0-51.8)$ & $79.8(70.6-98.0)$ & $<0.0001$ \\
BMI, kg/m & $113.2(99.3-134.8)$ & $30.6(26.9-36.1)$ & $<0.0001$ \\
AST, IU/L & $43.1(38.1-49.0)$ & $18.0(14.0-21.8)$ & $<0.0001$ \\
ALT, IU/L & $26.0(20.0-35.0)$ & $14.0(11.0-22.0)$ & $<0.0001$ \\
BUN, mg/dL & $32.5(20.0-53.3)$ & $14.2(10.7-16.8)$ & 0.8720 \\
Serum creatinine, mg/dL & $13.0(10.9-16.3)$ & $0.66(0.56-0.76)$ & 0.0016 \\
eGFR, mL/min/1.73 m² & $0.67(0.60-0.81)$ & $86.5(73.3-103.8)$ & 0.0083 \\
TC, mg/dL & $84.0(73.5-95.0)$ & $191.5(171.5-213.5)$ & 0.0024 \\
TG, mg/dL & $177.0(158.5-203.0)$ & $89.5(63.0-123.3)$ & $<0.0001$ \\
HDL-C, mg/dL & $133.5(100.3-185.0)$ & $62.0(54.0-74.0)$ & $<0.0001$ \\
LDL-C, mg/dL & $42.0(37.0-49.0)$ & $105.0(94.5-127.8)$ & 0.0317 \\
FBG, mg/dL & $110.0(97.0-131.8)$ & $96.5(90.3-107.8)$ & 0.0005 \\
HbA1c, \% & $105.0(94.5-120.0)$ & $5.6(5.3-5.9)$ & $<0.0001$ \\
\hline
\end{tabular}

Data are presented as median and IQR. LSG, laparoscopic sleeve gastrectomy; TWL, total weight loss; IGF-1, insulin-like growth factor-1; BW, body weight; BMI, body mass index; AST, aspartate transaminase; ALT, alanine transaminase; BUN, blood urea nitrogen; eGFR, estimated glomerular filtration rate; TC, total cholesterol; TG, triglycerides; HDL-C, high-density lipoprotein cholesterol; LDL-C, low-density lipoprotein cholesterol; FBG, fasting blood glucose; HbA1c, glycosylated hemoglobin; IQR, interquartile range. ${ }^{a}$ Wilcoxon signed-rank test.

Table 2. Body composition at baseline and 12 months after LSG

\begin{tabular}{|c|c|c|c|c|}
\hline & Baseline & After 12 months & $\begin{array}{l}\text { Difference between before } \\
\text { and } 12 \text { months after LSG }\end{array}$ & $p$ value $^{a}$ \\
\hline \multicolumn{5}{|l|}{ All patients, $n=72$} \\
\hline Body fat mass, $\mathrm{kg}$ & $50.3(42.9-64.7)$ & $30.6(20.5-43.5)$ & $-21.8(-29.9$ to -15.1$)$ & $<0.0001$ \\
\hline Normalized body fat mass, $\mathrm{kg} / \mathrm{m}^{2}$ & $19.7(16.4-24.0)$ & $11.5(7.0-15.8)$ & $-7.8(-11.0$ to -5.9$)$ & $<0.0001$ \\
\hline Skeletal muscle mass, $\mathrm{kg}$ & $52.7(46.3-67.0)$ & $48.4(41.1-61.4)$ & $-4.1(-7.0$ to -1.8$)$ & $<0.0001$ \\
\hline \multicolumn{5}{|l|}{ Male $(n=33)$} \\
\hline Free fat mass, kg & $71.1(63.6-81.6)$ & $67.3(59.3-76.1)$ & $-3.8(-7.4$ to -1.7$)$ & $<0.0001$ \\
\hline Body fat mass, $\mathrm{kg}$ & $54.5(42.3-77.0)$ & $31.3(17.4-48.2)$ & $-25.8(-36.4$ to -16.0$)$ & $<0.0001$ \\
\hline Normalized body fat mass, $\mathrm{kg} / \mathrm{m}^{2}$ & $20.0(14.3-26.6)$ & $11.2(6.0-17.1)$ & $-8.7(-12.5$ to -5.8$)$ & $<0.0001$ \\
\hline Skeletal muscle mass, $\mathrm{kg}$ & $67.3(60.0-77.3)$ & $63.8(56.1-71.8)$ & $-3.5(-7.2$ to -1.7$)$ & $<0.0001$ \\
\hline Normalized skeletal muscle mass, $\mathrm{kg} / \mathrm{m}^{2}$ & $23.1(20.7-24.3)$ & $21.7(19.7-23.1)$ & $-1.2(-2.5$ to -0.6$)$ & $<0.0001$ \\
\hline Skeletal muscle mass, $\mathrm{kg}$ & $46.9(41.9-49.8)$ & $41.7(39.3-44.6)$ & $-4.6(-7.0$ to -1.8$)$ & $<0.0001$ \\
\hline Normalized skeletal muscle mass, $\mathrm{kg} / \mathrm{m}^{2}$ & $18.7(17.7-20.0)$ & $17.0(16.2-17.6)$ & $-1.9(-2.7$ to -0.7$)$ & $<0.0001$ \\
\hline
\end{tabular}


Table 3. Correlation between the preoperative serum IGF-1 levels and body composition at baseline and 12 months after LSG

\begin{tabular}{|c|c|c|c|c|}
\hline & \multicolumn{4}{|c|}{ Preoperative IGF-1 } \\
\hline & \multicolumn{2}{|c|}{ univariate } & \multicolumn{2}{|l|}{ multivariate } \\
\hline & $\rho$ & $p$ value & standardized $\beta$ & $p$ value \\
\hline \multicolumn{5}{|l|}{ Preoperative } \\
\hline Age, years & -0.2328 & 0.0491 & -0.2698 & 0.0186 \\
\hline Sex (male; 0 , female; 1$)$ & -0.2544 & 0.0311 & -0.0516 & 0.6466 \\
\hline Type 2 diabetes (no; 0, yes; 1 ) & -0.0600 & 0.6168 & -0.1433 & 0.1826 \\
\hline BW, kg & -0.0429 & 0.7204 & & \\
\hline $\mathrm{BMI}, \mathrm{kg} / \mathrm{m}^{2}$ & -0.1880 & 0.1137 & & \\
\hline AST, IU/L & 0.0969 & 0.4179 & & \\
\hline $\mathrm{ALT}, \mathrm{IU} / \mathrm{L}$ & 0.1989 & 0.0939 & & \\
\hline Free fat mass, kg & 0.1065 & 0.3732 & & \\
\hline Body fat mass, $\mathrm{kg}$ & -0.2197 & 0.0637 & & \\
\hline Normalized body fat mass, $\mathrm{kg} / \mathrm{m}^{2}$ & -0.3321 & 0.0044 & & \\
\hline Skeletal muscle mass, $\mathrm{kg}$ & 0.0937 & 0.4336 & & \\
\hline Normalized skeletal muscle mass, $\mathrm{kg} / \mathrm{m}^{2}$ & -0.0295 & 0.8055 & & \\
\hline \multicolumn{5}{|l|}{ Postoperative } \\
\hline$\%$ TWL, \% & 0.2398 & 0.0425 & & \\
\hline$\Delta \mathrm{BW}, \mathrm{kg}$ & -0.1595 & 0.1807 & & \\
\hline$\Delta \mathrm{BMI}, \mathrm{kg} / \mathrm{m}^{2}$ & -0.1413 & 0.2366 & & \\
\hline$\triangle \mathrm{AST}, \mathrm{IU} / \mathrm{L}$ & -0.0338 & 0.7782 & & \\
\hline$\Delta \mathrm{ALT}, \mathrm{IU} / \mathrm{L}$ & -0.1072 & 0.3701 & & \\
\hline$\Delta$ Free fat mass, $\mathrm{kg}$ & 0.2488 & 0.0351 & & \\
\hline$\Delta$ Body fat mass, $\mathrm{kg}$ & -0.2764 & 0.0187 & & \\
\hline$\Delta$ Normalized body fat mass, $\mathrm{kg} / \mathrm{m}^{2}$ & -0.2436 & 0.0392 & -0.2405 & 0.0400 \\
\hline$\Delta$ Skeletal muscle mass, $\mathrm{kg}$ & 0.2515 & 0.0331 & & \\
\hline$\Delta$ Normalized skeletal muscle mass, $\mathrm{kg} / \mathrm{m}^{2}$ & 0.2809 & 0.0168 & 0.4399 & 0.0003 \\
\hline
\end{tabular}

Univariate analysis was performed using Spearman's rank correlation coefficient, owing to the nonparametric nature of a large volume of data. The multivariate analysis model was $r^{2}=0.2753$ and $p=0.0006 . \Delta$ is the difference between the baseline value and the value after 12 months. Normalized fat mass or skeletal muscle mass was estimated as fat mass or skeletal muscle mass/height $\left(\mathrm{m}^{2}\right)$. IGF-1, insulin-like growth factor-1; LSG, laparoscopic sleeve gastrectomy; BW, body weight; BMI, body mass index; AST, aspartate transaminase; ALT, alanine transaminase; TWL, total weight loss.

Twelve months after LSG, the median (IQR) \%TWL was $29.3 \%$ (22.6-35.3\%). BW and BMI values significantly decreased after LSG. TG, high-density lipoprotein cholesterol, low-density lipoprotein cholesterol, fasting blood glucose, and HbAlc levels significantly improved after LSG (Table 1). Table 2 shows body composition parameters at baseline and 12 months after LSG. Free fat mass, body fat mass, normalized body fat mass, skeletal muscle mass, and normalized skeletal muscle mass significantly decreased among all, male, and female patients $(p<$ $0.0001)$.

Table 3 shows the correlation between preoperative serum IGF-1 levels and clinical parameters and body composition at baseline and 12 months after LSG. We includ- ed the existence of type 2 diabetes because a clinical study showed that serum IGF-1 levels are different between obese patients with and without type 2 diabetes [24]. We also included AST and ALT, which may reflect liver fat, in this analysis, because circulating IGF-1 is associated with liver fat [25]. Univariate analysis showed that serum IGF-1 level significantly negatively correlated with age $(p=0.0491)$, sex $(p=0.0311)$, and preoperative normalized body fat mass $(p=0.0044)$. Preoperative serum IGF1 levels significantly positively correlated with \%TWL $(p=0.0425)$, change in free fat mass $(p=0.0351)$, skeletal muscle mass ( $p=0.0331$ ), and normalized skeletal muscle mass $(p=0.0168)$. Serum IGF-1 levels significantly negatively correlated with changes in body fat mass $(p=$ 
Table 4. Correlation between the preoperative serum IGF-1 levels and body composition at baseline and 12 months after LSG in men and women

\begin{tabular}{|c|c|c|c|c|}
\hline & \multicolumn{4}{|c|}{ Preoperative IGF-1 } \\
\hline & \multicolumn{2}{|c|}{ male $(n=33)$} & \multicolumn{2}{|c|}{ female $(n=39)$} \\
\hline & $\mathrm{P}$ & $p$ value & $\rho$ & $p$ value \\
\hline \multicolumn{5}{|l|}{ Preoperative } \\
\hline Age, years & -0.0695 & 0.7009 & -0.1993 & 0.2238 \\
\hline Type 2 diabetes (no; 0, yes; 1 ) & -0.0671 & 0.7106 & 0.0143 & 0.9314 \\
\hline BW, kg & -0.3348 & 0.0568 & -0.0917 & 0.5788 \\
\hline $\mathrm{BMI}, \mathrm{kg} / \mathrm{m}^{2}$ & -0.4290 & 0.0127 & -0.1395 & 0.3969 \\
\hline AST, IU/L & -0.0273 & 0.8803 & 0.1337 & 0.4172 \\
\hline$A L T, I U / L$ & 0.0458 & 0.8002 & 0.2608 & 0.1088 \\
\hline Free fat mass, kg & -0.2861 & 0.1065 & -0.0036 & 0.9827 \\
\hline Body fat mass, $\mathrm{kg}$ & -0.3734 & 0.0323 & -0.2343 & 0.1511 \\
\hline Normalized body fat mass, $\mathrm{kg} / \mathrm{m}^{2}$ & -0.4309 & 0.0123 & -0.2838 & 0.0800 \\
\hline Skeletal muscle mass, $\mathrm{kg}$ & -0.3084 & 0.0808 & -0.0087 & 0.9583 \\
\hline Normalized skeletal muscle mass, $\mathrm{kg} / \mathrm{m}^{2}$ & -0.4706 & 0.0057 & -0.1127 & 0.4946 \\
\hline \multicolumn{5}{|l|}{ Postoperative } \\
\hline \%TWL, \% & 0.1996 & 0.2654 & 0.2040 & 0.2128 \\
\hline$\Delta \mathrm{BW}, \mathrm{kg}$ & -0.0777 & 0.6673 & -0.0813 & 0.6228 \\
\hline$\Delta \mathrm{BMI}, \mathrm{kg} / \mathrm{m}^{2}$ & -0.1068 & 0.5542 & -0.0989 & 0.5491 \\
\hline$\triangle \mathrm{AST}, \mathrm{IU} / \mathrm{L}$ & 0.0713 & 0.6933 & -0.1226 & 0.4573 \\
\hline$\Delta \mathrm{ALT}, \mathrm{IU} / \mathrm{L}$ & -0.0475 & 0.7930 & -0.1351 & 0.4122 \\
\hline$\Delta$ Free fat mass, $\mathrm{kg}$ & 0.3939 & 0.0233 & 0.0860 & 0.6029 \\
\hline$\Delta$ Body fat mass, $\mathrm{kg}$ & -0.1530 & 0.3954 & -0.2587 & 0.1118 \\
\hline$\Delta$ Normalized body fat mass, $\mathrm{g} / \mathrm{m}^{2}$ & -0.1770 & 0.3245 & -0.2497 & 0.1253 \\
\hline$\Delta$ Skeletal muscle mass, $\mathrm{kg}$ & 0.3932 & 0.0236 & 0.0972 & 0.5560 \\
\hline$\Delta$ Normalized skeletal muscle mass, $\mathrm{kg} / \mathrm{m}^{2}$ & 0.3964 & 0.0224 & 0.1206 & 0.4646 \\
\hline
\end{tabular}

A simple linear regression analysis was performed using Spearman's rank correlation coefficient, owing to the nonparametric nature of a large volume of data. $\Delta$ is the difference between the baseline value and the value after 12 months. Normalized fat mass or skeletal muscle mass was estimated as fat mass or skeletal muscle mass/height $\left(\mathrm{m}^{2}\right)$. IGF-1, insulin-like growth factor-1; LSG, laparoscopic sleeve gastrectomy; BW, body weight; BMI, body mass index; TWL, total weight loss.

$0.0187)$ and change in normalized body fat mass $(p=$ 0.0392 ) after LSG.

In the multivariate analysis, the change in normalized skeletal muscle mass was a major independent predictor of preoperative serum IGF-1 levels $(p=0.0003)$. Age $(p=$ $0.0186)$ and change in normalized body fat mass $(p=$ 0.0400 ) were also independent predictors of preoperative serum IGF-1 levels. Sex and existence of type 2 diabetes were not independent predictors (Table 3 ).

We also analyzed the relationship between preoperative serum IGF-1 levels and body composition at baseline and 12 months after LSG in men and women because body composition differs between men and women [26]. There was a significant negative correlation of preoperative serum IGF-1 levels with BMI, body fat mass, normalized body fat mass, and normalized skeletal muscle mass at baseline and a positive correlation with change in free fat mass, skeletal muscle mass, and normalized skeletal muscle after LSG in men (Table 4). On the other hand, although correlation coefficients between body fat mass or normalized body fat mass and preoperative serum IGF-1 levels were about -0.25 , there was no significant correlation between preoperative serum IGF-1 levels and body composition changes in women (Table 4).

\section{Discussion/Conclusion}

In this study, LSG led to significant reductions in BW and BMI. LSG also decreased body fat mass, normalized body fat mass, skeletal muscle mass, and normalized skeletal muscle mass significantly. In the univariate analysis, 
preoperative serum IGF-1 levels were significantly correlated with preoperative normalized body fat mass, $\%$ TWL, changes in body fat mass, normalized body fat mass, skeletal muscle mass, and normalized skeletal muscle mass after LSG. The multiple regression model showed that age, change in normalized body fat mass, and change in normalized skeletal muscle mass were independent predictors of preoperative serum IGF-1 levels, and change in normalized skeletal muscle mass was the major independent predictor. Preoperative serum IGF-1 levels were significantly correlated with change in normalized skeletal muscle mass in male patients; however, they were not significantly correlated with preoperative serum IGF-1 levels and body composition change in female patients.

IGF-1 reflects patient GH secretion status [19]. GH exerts lipolytic action through extracellular signal-regulated kinases and signal transducer and activator of transcription 5-dependent mechanisms to control peroxisome proliferator-activated receptor- $\gamma$-mediated transcription of fat-specific protein 27. However, the lipolytic action of $\mathrm{GH}$ is direct and not associated with IGF-1 [27-30]. Serum IGF-1 levels were related to decreased body fat mass in this study, suggesting that IGF-1 reflects $\mathrm{GH}$ secretion and lipolytic action. Other studies have also shown a relationship between serum or plasma IGF-1 levels and body fat [31-33]. Fat mass is significantly higher [31], and the degree of fat mass change was significantly lower [32] in patients with IGF-1 deficiency or insufficiency than in those with IGF-1 normalcy after laparoscopic adjustable gastric banding. Plasma IGF-1 levels significantly negatively correlated with body fat percentage [33]. The results of previous studies and our study indicate that serum IGF-1 levels reflect the lipolytic effect of GH. Patients with sufficient serum IGF-1 levels are considered to adequately maintain $\mathrm{GH}$ secretion.

A previous study showed that serum IGF-1 level was related to preoperative BMI and \%TWL after LSG, rather than serum GH [15]. This can be attributed to 3 factors. First, the acute effect of lipolysis by GH is weaker, but its chronic effects are stronger in humans [34]. Second, GH has circadian changes, and a reduced mean $24-\mathrm{h}$ GH secretion value strongly correlates with an increased truncal fat mass [35]. Third, GH peaks after GH-releasing hormone + arginine were found to significantly correlate with the percentage of excess weight loss [28]. GH does not lipolyze immediately and its serum concentration changes easily; therefore, serum IGF-1 levels may be a better marker of body fat than GH.

The multiple regression analysis showed that preoperative serum IGF-1 levels were related to changes in skel- etal muscle mass. IGF-1 promotes myoblast proliferation and skeletal muscle growth via the PI3K/Akt signaling pathway $[36,37]$. Serum IGF-1 levels are significantly correlated with skeletal muscle mass [38]. In a mouse model, serum IGF-1 maintained skeletal muscle volume by activating Akt, extracellular signal-regulated kinases, Eif4e, and p70S6K [39]. In patients with acromegaly whose serum IGF-1 levels are quite high, skeletal muscle mass is significantly higher than in controls, and it significantly decreases 1 year after pituitary tumor resection [40]. Thus, serum IGF-1 levels are associated with changes in skeletal muscle mass.

Our study showed that preoperative serum IGF-1 levels were correlated with change in skeletal muscle mass after LSG in male patients; however, there was no correlation between preoperative serum IGF-1 levels and change in body composition after LSG in female patients. A clinical study showed that changes in body compositions after GH therapy in GH-deficient adults are different between men and women [41]. Baseline serum IGF-1 levels are related to increase in lean body mass and decrease in body fat in all patients; this was similar to our findings; however, lean body mass and body fat do not change significantly after $\mathrm{GH}$ therapy in female patients, despite the significant increase in IGF-1 levels [41]. This study and our study suggest that reactions of GH or/and IGF-1 may be different between men and women, but further study is needed to clarify this suggestion.

We showed that higher preoperative serum IGF-1 levels were significantly correlated with decreasing body fat mass and maintaining skeletal muscle mass after LSG. Age was significantly correlated with preoperative IGF-1 levels in both univariate and multivariate analyses. Although sex was also significantly correlated with IGF-1 levels only in the univariate analysis, age was significantly higher in women than in men. The correlation between IGF-1 levels and sex reflected the difference in age between men and women. Other variants such as BMI, liver enzymes, eGFR, and the existence of type 2 diabetes were not significantly correlated with preoperative serum IGF-1 levels. Therefore, age is an important determinant of preoperative IGF-1 levels. However, age was not significantly correlated with change in normalized body fat mass and normalized skeletal muscle mass after LSG ( $\Delta$ normalized body fat mass, $\rho=0.2179, p=0.0660 ; \Delta$ normalized skeletal muscle mass, $\rho=0.2034, p=0.0866$ ). Therefore, we considered that there are other determinants of preoperative serum IGF-1 levels. Except for age, we could not identify the other determinants in this study. Furthermore, IGF-1 has an effect on skeletal muscle hypertrophy and reflects the se- 
cretion of $\mathrm{GH}$, which has a lipolytic action, but we did not measure postoperative serum IGF-1 levels in this study. If we measured postoperative serum IGF-1 levels, we would have clarified the effect of IGF-1 on body fat mass and skeletal muscle mass after LSG. Therefore, we considered that we showed 1 cause of a decrease in body fat and maintenance of skeletal muscle mass after LSG.

Body composition is generally measured using dual energy X-ray absorptiometry (DXA) for obese patients in clinical settings. We evaluated body composition by BIA using InBody device in this study. Although InBody is not acceptable for individual estimates of body composition in an obese patient, like DXA, InBody could be used for estimating group body composition (body fat percent and free fat mass) [42]. Furthermore, like DXA, InBody can predict changes in body composition between preand post-treatment of energy reduction and exercise [43]. However, InBody shows the systematic bias and proportional bias when estimating fat mass in women and free fat mass in men [44]. We used the same device before and 12 months after LSG. We considered that these biases were similar for both measurements in this study. The reported coefficient of variation of InBody is $1.8 \%$ [45]. Thus, we considered that BIA using InBody could be used to evaluate body composition in this study.

This study has some limitations. First, we did not measure IGF-1 levels after LSG. Hormone level measurements, including GH and IGF-1, were performed only at the preoperative stage as it was aimed at the discrimination of secondary obesity. Therefore, we could not evaluate the relationship between changes in body composition and IGF- 1 levels after LSG. Second, the physiological decrease in IGF-1 among patients with obesity without GH deficiency usually increases after weight loss or bariatric surgery. In this study, in some participants with lower preoperative IGF-1 levels, IGF-1 levels might not have increased after LSG. However, we did not measure the serum IGF-1 levels 12 months after LSG. Hence, we could not ascertain the degree of change in IGF-1 levels after LSG. Finally, since this was a single-center retrospective study, the sample size was limited. Future studies are needed that include a larger number of patients with obesity, the addition of a control group, and the use of multiple medical centers in Japan and possibly other Asian countries. Despite these limitations, we were able to show that preoperative serum IGF-1 level was associated with maintaining skeletal muscle mass and a decrease in body fat after LSG.

In conclusion, preoperative serum IGF-1 level is related to maintaining skeletal muscle mass and decreasing body fat mass. IGF-1 measurement in the preoperative state helps predict not only successful weight loss but also the maintenance of skeletal muscle mass and a decrease in body fat after LSG.

\section{Acknowledgment}

The authors are grateful to Sayaka Tsuji (Center for Diabetes, Endocrinology, and Metabolism, Toho University Sakura Medical Center, Sakura City, Chiba, Japan), a coordinator, for her assistance with patient care.

\section{Statement of Ethics}

This study was performed in accordance with the Declaration of Helsinki and was approved by the Ethics Committee of Toho University Sakura Medical Center (approval date: November 28, 2018; approval No. S18061). Although this was a retrospective study, we individually explained the issue of use and release of study data before the operation, and written consent was obtained in each case.

\section{Conflict of Interest Statement}

The authors declare that they have no conflicts of interest.

\section{Funding Sources}

No funding was received for this study.

\section{Author Contributions}

M.O. contributed to the research concept and design, collection and/or assembly of data, data analysis, and writing of the article. Y.W. contributed to collection and/or assembly of data. T.Y. contributed to collection and/or assembly of data. H.O. contributed to collection and/or assembly of data. S.Y. contributed to collection and/or assembly of data. K.A. contributed to collection and/or assembly of data. S.N. contributed to collection and/or assembly of data. S.T. contributed to collection and/or assembly of data. N.K contributed to collection and/or assembly of data. T.N. contributed to collection and/or assembly of data. A.S. contributed to collection and/or assembly of data and critical revision of the manuscript. T.O. contributed to collection and/or assembly of data. D.N. contributed to data interpretation. I.T. contributed to data interpretation and critical revision of the manuscript. All authors approved the version to be published.

\section{Data Availability Statement}

Data generated and/or analyzed during this research are available from the corresponding author on reasonable request. 


\section{References}

1 Armstrong J, O’Malley SP. Outcomes of sleeve gastrectomy for morbid obesity: a safe and effective procedure? Int J Surg. 2010;8(1): 69-71.

2 Arias E, Martínez PR, Ka Ming Li V, Szomstein S, Rosenthal RJ. Mid-term follow-up after sleeve gastrectomy as a final approach for morbid obesity. Obes Surg. 2009 May;19(5): 544-8.

3 Karamanakos SN, Vagenas K, Kalfarentzos F, Alexandrides TK. Weight loss, appetite suppression, and changes in fasting and postprandial ghrelin and peptide-YY levels after Roux-en-Y gastric bypass and sleeve gastrectomy: a prospective, double blind study. Ann Surg. 2008 Mar;247(3):401-7.

4 Han SM, Kim WW, Oh JH. Results of laparoscopic sleeve gastrectomy (LSG) at 1 year in morbidly obese Korean patients. Obes Surg. 2005;15(10):1469-75.

5 Amin A, Siddiq G, Haider MI, Khalid Choudry U, Nazir I. Laparoscopic sleeve gastrectomy versus lifestyle modification in class I obesity in Pakistani population: a prospective cohort study. Cureus. 2019 Jun;11(6): e5031.

6 Ohira M, Yamaguchi T, Saiki A, Nakamura S, Tanaka S, Oka R, et al. Laparoscopic sleeve gastrectomy significantly increases serum lipoprotein lipase level in obese patients. Obes Facts. 2019;12(3):357-68.

7 Saiki A, Yamaguchi T, Tanaka S, Sasaki A, Naitoh T, Seto Y, et al. Background characteristics and postoperative outcomes of insufficient weight loss after laparoscopic sleeve gastrectomy in Japanese patients. Ann Gastroenterol Surg. 2019 Aug;3(6):638-47.

8 Sieber P, Gass M, Kern B, Peters T, Slawik M, Peterli R. Five-year results of laparoscopic sleeve gastrectomy. Surg Obes Relat Dis. 2014;10(2):243-9.

9 Catheline JM, Fysekidis M, Bachner I, Bihan $\mathrm{H}$, Kassem A, Dbouk R, et al. Five-year results of sleeve gastrectomy. J Visc Surg. 2013 Nov; 150(5):307-12.

10 Al-Khyatt W, Ryall R, Leeder P, Ahmed J, Awad S. Predictors of inadequate weight loss after laparoscopic gastric bypass for morbid obesity. Obes Surg. 2017 Jun;27(6):1446-52.

11 Keith CJ Jr, Gullick AA, Feng K, Richman J, Stahl R, Grams J. Predictive factors of weight regain following laparoscopic Roux-en-Y gastric bypass. Surg Endosc. 2018 May;32(5): 2232-8.

12 Lee YC, Lee WJ, Lee TS, Lin YC, Wang W, Liew PL, et al. Prediction of successful weight reduction after bariatric surgery by data mining technologies. Obes Surg. 2007 Sep;17(9): 1235-41.

13 Nickel F, de la Garza JR, Werthmann FS, Benner L, Tapking C, Karadza E, et al. Predictors of risk and success of obesity surgery. Obes Facts. 2019;12(4):427-39.
14 Saboor Aftab SA, Halder L, Piya MK, Reddy N, Fraser I, Menon V, et al. Predictors of weight loss at 1 year after laparoscopic adjustable gastric banding and the role of presurgical quality of life. Obes Surg. 2014 Jun;24(6): 885-90.

15 Ohira M, Watanabe Y, Yamaguchi T, Saiki A, Oshiro T, Tatsuno I. Low serum insulin-like growth factor-1 level is a predictor of low total weight loss percentage after sleeve gastrectomy. Surg Obes Relat Dis. 2020 Dec;16(12): 1978-87.

16 Pellitero S, Granada ML, Martínez E, Balibrea JM, Guanyabens E, Serra A, et al. IGF1 modifications after bariatric surgery in morbidly obese patients: potential implications of nutritional status according to specific surgical technique. Eur J Endocrinol. 2013 Oct;169(5): 695-703.

17 Hussain MA, Schmitz O, Mengel A, Keller A, Christiansen JS, Zapf J, et al. Insulin-like growth factor I stimulates lipid oxidation, reduces protein oxidation, and enhances insulin sensitivity in humans. J Clin Invest. $1993 \mathrm{Nov}$ 92(5):2249-56.

18 Bergan-Roller HE, Sheridan MA. The growth hormone signaling system: insights into coordinating the anabolic and catabolic actions of growth hormone. Gen Comp Endocrinol. 2018 Mar;258:119-33.

19 Frystyk J. Free insulin-like growth factors measurements and relationships to growth hormone secretion and glucose homeostasis. Growth Horm IGF Res. 2004 Oct;14(5):33775.

20 Fain JN. Studies on the role of RNA and protein synthesis in the lipolytic action of growth hormone in isolated fat cells. Adv Enzyme Regul. 1967;5:39-51.

21 Sengupta K, Long KJ, Allen DO. Growth hormone stimulation of lipolysis and cyclic AMP levels in perifused fat cells. J Pharmacol Exp Ther. 1981 Apr;217(1):15-9.

22 Sullivan PA, Still CD, Jamieson ST, Dixon CB, Irving BA, Andreacci JL. Evaluation of multifrequency bioelectrical impedance analysis for the assessment of body composition in individuals with obesity. Obes Sci Pract. 2018 Dec;5(2):141-7.

23 de Oliveira PAP, Montenegro ACP, Bezerra LRA, da Conceição Chaves de Lemos M, Bandeira F. Body composition, serum sclerostin and physical function after bariatric surgery: performance of dual-energy X-ray absorptiometry and multifrequency bioelectrical impedance analysis. Obes Surg. 2020 Aug;30(8): 2957-62.

24 Poulos JE, Leggett-Frazier N, Khazanie P, Long S, Sportsman R, MacDonald K, et al. Circulating insulin-like growth factor I concentrations in clinically severe obese patients with and without NIDDM in response to weight loss. Horm Metab Res. 1994 Oct; 26(10):478-80.
25 Runchey SS, Boyko EJ, Ioannou GN, Utzschneider KM. Relationship between serum circulating insulin-like growth factor-1 and liver fat in the United States. J Gastroenterol Hepatol. 2014 Mar;29(3):589-96.

26 Wells JC. Sexual dimorphism of body composition. Best Pract Res Clin Endocrinol Metab. 2007 Sep;21(3):415-30.

27 Sharma R, Luong Q, Sharma VM, Harberson M, Harper B, Colborn A, et al. Growth hormone controls lipolysis by regulation of FSP27 expression. J Endocrinol. 2018 Dec; 239(3):289-301.

28 Sharma VM, Vestergaard ET, Jessen N, Kolind-Thomsen P, Nellemann B, Nielsen TS, et al. Growth hormone acts along the PPAR $\gamma$-FSP27 axis to stimulate lipolysis in human adipocytes. Am J Physiol Endocrinol Metab. 2019 Jan;316(1):E34-42.

29 List EO, Berryman DE, Funk K, Jara A, Kelder $\mathrm{B}$, Wang F, et al. Liver-specific $\mathrm{GH}$ receptor gene-disrupted (LiGHRKO) mice have decreased endocrine IGF-1, increased local IGF1 , and altered body size, body composition, and adipokine profiles. Endocrinology. 2014 May;155(5):1793-805.

30 Kopchick JJ, Berryman DE, Puri V, Lee KY, Jorgensen JOL. The effects of growth hormone on adipose tissue: old observations, new mechanisms. Nat Rev Endocrinol. 2020 Mar;16(3):135-46.

31 Savastano S, Angrisani L, Di Somma C, Rota F, Savanelli MC, Cascella T, et al. Relationship between growth hormone/insulin-like growth factor-1 axis integrity and voluntary weight loss after gastric banding surgery for severe obesity. Obes Surg. 2010 Feb;20(2): 211-20.

32 Di Somma C, Angrisani L, Rota F, Savanelli MC, Cascella T, Belfiore A, et al. GH and IGFI deficiency are associated with reduced loss of fat mass after laparoscopic-adjustable silicone gastric banding. Clin Endocrinol. 2008 Sep;69(3):393-9.

$33 \mathrm{Hu}$ HY, Yamamoto H, Sohmiya M, Abe T, Murakami Y, Kato Y. Body composition assessed by bioelectrical impedance analysis (BIA) and the correlation with plasma insulin-like growth factor I (IGF-I) in normal Japanese subjects and patients with acromegaly and GH deficiency. Endocr J. 1994 Feb;41(1): 63-9.

34 Carmean CM, Cohen RN, Brady MJ. Systemic regulation of adipose metabolism. Biochim Biophys Acta. 2014 Mar;1842(3):424-30.

35 Miller KK, Biller BM, Lipman JG, Bradwin G, Rifai N, Klibanski A. Truncal adiposity, relative growth hormone deficiency, and cardiovascular risk. J Clin Endocrinol Metab. 2005 Feb;90(2):768-74.

36 Vassilakos G, Barton ER. Insulin-like growth factor I regulation and its actions in skeletal muscle. Compr Physiol. 2018 Dec;9(1):41338. 
37 Yu M, Wang H, Xu Y, Yu D, Li D, Liu X, et al. Insulin-like growth factor-1 (IGF-1) promotes myoblast proliferation and skeletal muscle growth of embryonic chickens via the PI3K/Akt signaling pathway. Cell Biol Int. 2015 Aug;39(8):910-22.

38 Andersen M, Brixen K, Hagen C, Frystyk J, Nielsen TL. Positive association between serum levels of IGF-1 and subcutaneous fat depots in young men. The Odense Androgen Study. Growth Horm IGF Res. 2012;22(3-4): 139-45.

39 Nakamura S, Sato Y, Kobayashi T, Oike T, Kaneko Y, Miyamoto K, et al. Insulin-like growth factor-I is required to maintain muscle volume in adult mice. J Bone Miner Metab. 2019 Jul;37(4):627-35.
40 Guo X, Gao L, Shi X, Li H, Wang Q, Wang $Z$, et al. Pre- and postoperative body composition and metabolic characteristics in patients with acromegaly: a prospective study. Int J Endocrinol. 2018 Jan;2018: 4125013.

41 Hayes FJ, Fiad TM, McKenna TJ. Gender difference in the response of growth hormone (GH)-deficient adults to GH therapy. Metabolism. 1999 Mar;48(3):308-13.

42 Nickerson BS, McLester CN, McLester JR, Kliszczewicz BM. Agreement between 2 segmental bioimpedance devices, BOD POD, and DXA in obese adults. J Clin Densitom. 2020 Jan-Mar;23(1):138-48.

43 Antonio J, Kenyon M, Ellerbroek A, Carson C, Burgess V, Tyler-Palmer D, et al. Compar- ison of dual-energy X-ray absorptiometry (DXA) versus a multi frequency bioelectrical impedance (in body 770) device for body composition assessment after a 4-week hypoenergetic diet. J Funct Morphol Kinesiol. 2019 Apr;4(2):23.

44 McLester CN, Nickerson BS, Kliszczewicz BM, McLester JR. Reliability and agreement of various Inbody body composition analyzers as compared to dual-energy X-ray absorptiometry in healthy men and women. J Clin Densitom. 2020 Jul-Sep;23(3):443-50.

45 Jensky-Squires NE, Dieli-Conwright CM, Rossuello A, Erceg DN, McCauley S, Schroeder ET. Validity and reliability of body composition analysers in children and adults. $\mathrm{Br} \mathrm{J}$ Nutr. 2008 Oct;100(4):859-65. 